be so well plotted on this last survey that the amount of gorge excavated since 1750 should be knowable to an acre. The west fall, then, only slightly the larger, has ever since been widening, lowering its edge, and getting more of the stream; so that the east one, comparatively stationary, retaining its height and decreasing in volume, must dry up, and its bed and all the isles become part of New York State.

July I I

E. L. Garbett

\section{Sky Glows}

EVER since the sunsets of $\mathrm{I} 883$ and last year there has been at times an abnormal glare both before and after sundown. But I have seen nothing in the way of twilight effect so strange as that of Monday evening, the 6th, when about ro p.m. a sea of luminous silvery white clond lay above a belt of ordinary clear twilight sky, which was rather low in tone and colour. These clouds were wave-like in form, and evidently at a great elevation, and though they must have received their light from the sun, it was not easy to think so, as upon the dark sky they looked brighter and paler than clouds under a full moon. A friend who was with me aptly compared the light on these clouds to that which shines from white phosphor paint. This effect lasted for some time after Io p.m., and extended from west to north, the lower edge of the clouds, which was sharply defined, was about $12^{\circ}$ above the horizon.

6, Moira Place, Southampton, July 8

\section{Black and White}

MY daughter has two terriers, one black, the other white; she has noticed that in the dusk of the evening the black dog is much more visible than the white one, and has asked me the reason for this fact. I cannot properly explain why a white or light coloured garment shows much less in the dusk than a dark coloured dress, but this is a well-known fact to all sportsmen who shoot ducks at night, when it is their custom to wear a night shirt or other white dress over their ordinary costume. When the black and white dogs are playing together in the dusk of evening, the black dog can be distinctly seen when the white dog, at the same distance, is quite invisible. Will you please explain this?

Bught, Inverness, July 8

\section{"Foul Water"}

DURING a brief stay at Beaumaris in June I883, and again in June I884, I had frequent opportunities of observing the "gelatinous masses" mentioned by Mr. Shrubsole as occurring in large numbers at Sheerness-on-Sea. I first noticed them in I883, while procuring a supply of water for my marine tanks at home. They then existed in very large numbers, and as I had no means of filtering the water before returning to Manchester, I almost expected to find it "foul" upon my arrival. I was, however, agreeably disappointed. The "gelatinous masses" had settled at the bottom of the jars, and were apparently dead. While at Beaumaris I subjected a few specimens to microscopical examination, but being busy with other work did not learn more than is given in Mr. Shrubsole's description.

Manchester Herbert C. ChaDWICK

\section{Eartbquake-Proof Buildings}

UNLESS my memory plays me very false a number of lighthouses secured against earthquake shocks by saucers and balls were built in Japan just about twenty years ago from the designs of Mr. Stevenson of Edinburgh.

The London Institution, Finsbury Circus, E.C.

\section{THE QUESTION OF CIVIL AND ASTRONOMICAL TIME}

$\mathrm{NE}$ of the points made at the Washington Congress was that if Universal Time (surely Earth-Time or Prime Meridian 'Time would be a better term) were generally accepted, astronomical time might be abolished, astronomers accepting the new day of twenty-four hours commencing at midnight

Since the Congress the question naturally has been well considered, and we think it desirable that we should now refer to some of the most important opinions which have already been given, not only as regards the desirability of the change, but as to the time at which that change should be brought about.

Among the first to accept the resolution was the Astronomer-Royal, for theinternal use of the Observatory of Greenwich. Many opinions were collected at an early date and forwarded by Mr. Chandler, the Secretary of the U.S. Navy to the Senate. This action grew out of an order of Commodore Franklin, the Superintendent of the U.S. Naval Observatory, to adopt the new time on January I, I885; this was communicated to Prof. Newcomb, the Superintendent of the American Nautical Almanac, and drew a reply from Prof. Newcomb, from which we make the following extract:-

"(I) The Conference expresses the hope that as soon as may be practical the astronomical and nautical days will be arranged everywhere to begin at mean midnight.

"(2) That east longitudes shall be counted as plus and west longitudes as minus.

"The first of these recommendations proposes a change in the method of counting astronomical time which has come down to us from antiquity, and which is now universal among astronomers. The practice of taking noon as the moment from which the hours were to be counted originated with Ptolemy. This practice is not, as some distinguished members of the Conference seem to have supposed, based solely upon the inconvenience to the astronomer of changing his day at midnight, but was adopted because it was the most natural method of measuring solar time. At any one place solar time is measured by the motion of the sun, and is expressed by the sun's hour angle. By uniform custom hour angles are reckoned from the meridian of the place, and thus by a natural process the solar day is counted from the moment at which the sun passes over the meridian of the place or over the standard meridian. For the same reason sidereal time is counted from the moment at which the vernal equinox passes over the meridian of the place, and thus the two times correspond to the relation between the sun and the equinox.

"It would appear that the Conference adopted the recommendation under the impression that the change would involve nothing more than the current method of reckoning time among astronomers, and could therefore be made without serious inconvenience. A more mature consideration than time permitted the Conference to devote to the subject would, I am persuaded, have led that distinguished body to a different conclusion.

"A change in the system of reckoning astronomical time is not merely a change of habit, such as a new method of counting time in civil life would be, but a change in the whole literature and teaching of the subject. The existing system permeates all the volumes of ephemerides and observations which fill the library of the astronomer. All his text-books, all his teachings, his tables, his formul:e, and his habits of calculation are based on this system. To change the system will involve a change in many of the precepts and methods laid down in his text-books.

"But this would only be the beginning of the confusion. Astronomical observations and ephemerides are made and printed not only for the present time, but for future generations and for future centuries. If the system is changed as proposed the astronomers of future generations who refer to these publications must bear the change in mind in order not to misinterpret the data before them. The case will be yet worse if the change is not made by all the ephemerides and astronomers at the same time epoch. It will then be necessary for the astronomers of the twentieth century, using ephemerides and observations of the present, to know, remember, and have constantly in mind a certain date different in each case at which the change was made. For example, if, as is officially announced, the Naval Observatory introduces the new system on January I, I 885 , then there will be for several years a lack of correspondence between the system of that establishment and the system of the American Ephemeris, which is prepared four years in advance.

"It is difficult to present to others than astronomers who have made use of published observations the confusion, embarrassments, and mistakes that will arise to their successors from the change. The case can be illustrated perhaps by saying that it is of the same kind as-though in less degree than-the confusion that would arise to readers and historians in the future if 